\title{
Emerging treatment options for psoriasis
}

\author{
This article was published in the following Dove Press journal: \\ Psoriasis: Targets and Therapy \\ 18 August 2014 \\ Number of times this article has been viewed
}

\author{
Arash Taheri' \\ Laura F Sandoval' \\ Sara Moradi Tuchayi' \\ Hossein Alinia' \\ Parisa Mansoori ${ }^{2}$ \\ Steven R Feldman ${ }^{1-3}$ \\ 'Center for Dermatology Research, \\ Department of Dermatology, \\ ${ }^{2}$ Department of Pathology, \\ ${ }^{3}$ Department of Public Health \\ Sciences, Wake Forest School of \\ Medicine, Winston-Salem, NC, USA
}

Correspondence: Sara Moradi Tuchayi

Department of Dermatology,

Wake Forest School of Medicine,

4618 Country Club Road, Winston-Salem,

NC 27104, USA

Tel +I 3367167740

Fax + I 3367167732

Email samo_1985@yahoo.com
Abstract: The treatment of psoriasis has evolved over the years, with the recent focus largely on the use of biologics and anti-interleukin-17 agents. With treatment options expanding, practitioners and patients may find control of psoriasis more convenient and safer to achieve. In this article, we review the literature on emerging medications for the treatment of psoriasis. Although some of the new medications under development, such as the anti-interleukin-17 agents, are being shown to be very efficacious in the treatment of psoriasis in premarketing trials, more information regarding their long-term use is needed to demonstrate their superiority over available modalities.

Keywords: psoriasis, therapy, interleukin-17, biologics, emerging, treatment

\section{Introduction}

Psoriasis and psoriatic arthritis are chronic inflammatory diseases affecting about $2 \%-4 \%$ of the population in Western countries. ${ }^{1,2}$ These conditions can severely affect quality of life for patients and usually require long-term topical or systemic treatment. ${ }^{2-5}$ Systemic treatments, including oral, parenteral, and biologic agents, and phototherapy are used to treat moderate-to-severe disease. Treatment guidelines for the management of psoriasis exist and can help practitioners make evidence-based recommendations. Systemic therapies are recommended in patients when adequate control of disease cannot be accomplished with topical agents. ${ }^{6-8}$ While measures of disease severity, such as body surface area, are helpful in determining appropriate treatment regimes, the patient's perception of disease burden should determine whether systemic medications might be considered. ${ }^{7,9,10}$ Although individualized treatment based on patients' needs is emphasized for the treatment of skin psoriasis, in psoriatic arthritis, prevention of joint destruction and disability should be considered and discussed with the patient.

Although there are many topical and systemic antipsoriatic medications available, patients and practitioners often experience problems controlling psoriasis, because of lack of efficacy, development of adverse effects, difficulty in using treatments, or cost of therapies. Drug manufacturers and researchers are searching for new medications with better efficacy/risk profiles that can be used easily.

Systemic treatment of psoriasis has evolved over the years, with the current focus largely on agents used to block specific pathways of inflammation. Traditional systemic drugs, including methotrexate, cyclosporine, and acitretin, have remained relatively unchanged for many years. The end-organ toxicity and/or teratogenicity 
of these oral medications limit their use, and may deter practitioners from providing systemic treatment, even for severe psoriasis. ${ }^{9}$ Biologics target specific cytokines or immune cells. Their therapeutic exclusiveness results in a limited side effect profile compared with traditional systemic immunosuppressive agents and antipsoriatic drugs. Currently, the main emphasis of research is on biologics, with newer agents targeting interleukin (IL)-17, one of the key cytokines in the pathogenesis of psoriasis, and on new oral agents in development. ${ }^{7}$ As the treatment options for psoriasis expand, with new oral and injectable agents in development, physicians need to have a knowledge of the pharmacodynamics, efficacy, and adverse effects of emerging medications. This paper reviews the recent studies and literature on new medications used for psoriasis.

\section{Methods}

A review of the literature was conducted from January 1, 2012 through May 1, 2014 to identify all randomized clinical trials and review articles on the treatment of psoriasis. PubMed was searched using the terms "psoriasis treatment" and "psoriasis therapy", and the results were limited to clinical trials and review articles. Publications in languages other than English were excluded. Medication in Phase I, II, or III clinical trials for psoriasis and not yet approved for psoriasis were included, summarized, and reported according to the mechanism of action of the study drug. Many emerging agents in Phase I-III clinical trials for the treatment of psoriasis were identified (Table 1).

\section{New small molecules for treatment of psoriasis}

Several small molecules are under investigation for treatment of psoriasis, including A3 adenosine receptor agonists, Janus kinase (JAK) inhibitors, phosphodiesterase inhibitors, and some new anti-inflammatory agents. Many of these small molecules can be used orally, and may be more convenient than injectable drugs.

\section{$\mathrm{A} 3$ adenosine receptor agonists}

The A3 adenosine receptor (A3AR) is highly expressed in inflammatory cells, including in peripheral blood mononuclear cells in patients with psoriasis, rendering the A3AR a potential therapeutic target in inflammatory diseases. ${ }^{15}$ This receptor exerts its anti-inflammatory effects by inhibiting the proliferation of specific autoreactive $\mathrm{T}$ lymphocytes and downregulating the NF- $\mathrm{KB}$ signaling pathway, resulting in downregulation of proinflammatory
Table I Drugs in development for treatment of psoriasis

\begin{tabular}{llll}
\hline $\begin{array}{l}\text { DrugI } \\
\text { compound }\end{array}$ & Phase & Mechanism of action & Type \\
\hline CNTO I959 & II & Anti-IL-23 (pI9) & Biologic \\
MK-3222 & III & Anti-IL-23 (pI9) & Biologic \\
SCH900222 & II & Anti-IL-23 (PI9) & Biologic \\
APG2305 & II & Anti-IL-23 receptor & Small molecule \\
Apilimod & II & IL-I2/IL-23 expression & Small molecule \\
& & inhibitor & \\
Brodalumab & III & Anti-IL-I7RA receptor & Biologic \\
Ixekizumab & III & Anti-IL-I7A & Biologic \\
Secukinumab & III & Anti-IL-I7A & Biologic \\
Itolizumab & III & Anti-CD6 & Biologic \\
BT-06I & II & Ab against an epitope & Biologic \\
& & on CD4 & \\
AbGn-I68 & II & Anti-PSGL-I & Biologic \\
AEB07I & II & PKC inhibitor & Small molecule \\
FPI87 & II & Fumaric acid & Small molecule \\
Leo 228II & II & Anti-inflammatory & Small molecule \\
ACT-I28800 & II & SIP agonist & Small molecule \\
VB-20I & II & Immune modifier & Small molecule \\
BMS582949 & II & P38 inhibitor & Small molecule \\
SRT2I04 & II & Sirtuin activator & Small molecule \\
Erlotinib & II & Anti-EGFR & Small molecule \\
RWJ-445380 & II & Cathepsin S inhibitor & Small molecule \\
R342I & II & Purine nucleoside & Small molecule \\
(BCX-4208) & & phosphorylase inhibitor & \\
CFI0I & II & Adenosine receptor & Small molecule \\
& & agonist & \\
Tofacitinib & III & JAK inhibitor & Small molecule \\
Baricitinib & II & JAK inhibitor & Small molecule \\
ASP0I5K & II & JAK inhibitor & Small molecule \\
Ruxolintinib & I & JAK inhibitor & Small molecule \\
Apremilast & III & Phosphodiesterase-4 & Small molecule \\
& & inhibitor & \\
AN2728 & I & Phosphodiesterase-4 & Small molecule \\
Noclorin & III & Calcineurin inhibitor & Small molecule \\
\hline
\end{tabular}

Notes: Data from Sandoval et al, ${ }^{7}$ Krupashankar et al," Laws and Young, ${ }^{12}$ Gooderham, ${ }^{13}$ and Patel et al. ${ }^{14}$

Abbreviations: IL, interleukin; PSGL-I, P-selectin glyocoprotein ligand-I; PKC, protein kinase C ; SIP, sphingosine-I-phosphate (SIP) receptor; P38, P38 mitogenactivated protein kinases; EGFR, epidermal growth factor receptor; JAK, janus kinase; TrkA, neurotrophic tyrosine kinase receptor type I; MEK, Mitogen-activated protein kinase kinase.

cytokines and chemokines and in apoptosis of inflammatory cells. ${ }^{16-19}$

In a Phase II study of CF101, an oral A3AR agonist, 35\% of patients with moderate-to-severe plaque psoriasis receiving a $2 \mathrm{mg}$ dose twice daily achieved at least 50\% improvement in their Psoriasis Area and Severity Index (PASI) score at week 12. ${ }^{16}$ Although this degree of efficacy seems to be less than that of methotrexate or biologics, improvement was significantly better in the treatment group when compared with placebo group in this study. Reported side effects were mild. The 
authors concluded that CF101 has potential in the treatment of psoriasis, but that larger clinical trials are needed. ${ }^{16}$

\section{JAK inhibitors}

Preclinical studies have indicated that a significant number of the cytokines involved in the pathogenesis of psoriasis utilize the JAK signaling pathway to mediate their inflammatory immune responses and to regulate the proliferation and differentiation of immune cells. ${ }^{20-25}$ Tofacitinib is an inhibitor of the JAK1 and JAK3 signaling pathway. Inhibition of JAK3 blocks signal transduction of a number of cytokines (IL-2, 4, 7, 9, 15, and 21), resulting in modulation of lymphocyte function and survival. ${ }^{20-25}$ In a Phase II study of oral tofacitinib in patients with moderate-to-severe plaque psoriasis, a 75\% improvement in PASI (PASI-75) response was achieved in $67 \%$ of patients treated with $15 \mathrm{mg}$ orally twice daily at week $12 .{ }^{24}$ Improvement was significantly greater in tofacitinib-treated patients at all doses compared with placebo. Greater improvement was also seen in other efficacy and quality of life measures, including PASI-90, Physician's Global Assessment (PGA), and Daily Life Quality Index (DLQI) for all doses. Tofacitinib was generally well tolerated with few side effects reported. ${ }^{24}$

A topical formulation of tofacitinib is also under development, with an ointment having been evaluated in a Phase II multicenter, double-blind, vehicle-controlled trial. ${ }^{26}$ Seventy-one patients were randomized to $2 \%$ tofacitinib ointment or to a vehicle group, each administered twice daily for 4 weeks to a single target plaque. The change in Target Plaque Severity Score at week 4 demonstrated a statistically significant improvement for the ointment $(-54 \%)$ versus vehicle $(-41 \%)$. The target plaque area and Itch Severity Item also improved in a similar way. All adverse events were mild or moderate, and none were serious or led to subject discontinuation. Systemic tofacitinib exposure was minimal. ${ }^{26}$

INCB18424 (ruxolitinib) is another emerging topical drug in this group. It preferentially inhibits JAK1 and JAK2 compared with JAK3. INCB018424 inhibits mainly IL-17, 20 , and 22 , as well as interferon-gamma. ${ }^{27}$ In a recent clinical study, application of INCB018424 cream for 28 days resulted in a decrease in mean total lesion score by $54 \%$ compared with $32 \%$ for vehicle $(P=0.033)$. INCB018424 was well tolerated, with few mild adverse events reported. ${ }^{27}$

\section{Phosphodiesterase inhibitors}

Agents that increase intracellular cyclic adenosine monophosphate have an antagonistic effect on proinflammatory molecules and can reduce production of the proinflammatory mediators involved in psoriasis, such as tumor necrosis factor-alpha (TNF- $\alpha$ ), IL-23, and interferon. ${ }^{28-30}$ While many such inhibitors have been developed, their use is limited by side effects such as nausea and vomiting, reported at subtherapeutic levels. The latest generation of inhibitors selective for phosphodiesterase 4, such as apremilast, seems to have an improved therapeutic index. ${ }^{30-32}$ Apremilast, an oral small molecule inhibitor of phosphodiesterase 4 , is under development for the treatment of psoriatic arthritis, psoriasis, ankylosing spondylitis, Behçet's syndrome, atopic dermatitis, and rheumatoid arthritis. Apremilast has recently received its first approval for active psoriatic arthritis in adults in the USA. Apremilast was studied in patients with psoriasis in a Phase II clinical trial. At week $16,41 \%$ of patients with plaque psoriasis receiving oral apremilast $30 \mathrm{mg}$ twice daily achieved a PASI-75 response compared with $6 \%$ of patients on placebo $(P<0.0001) .{ }^{29}$ In a Phase IIb trial, treatment with apremilast resulted in a significant improvement in health-related quality of life scores, including DLQI and pruritus over 16 weeks of treatment, in patients with moderate-to-severe psoriasis. ${ }^{33}$ Gastrointestinal side effects continued to be reported, the most common being headache, nausea, diarrhea, and vomiting. In a recent Phase III study of this drug for plaque-type psoriasis, 33\% of patients demonstrated a PASI-75 at week 16 compared with $5 \%$ in the placebo arm. ${ }^{34}$

\section{Other new anti-inflammatory agents}

WBI-1001 (2-isopropyl-5-[(E)-2-phenylethenyl]benzene1,3-diol) is a topical nonsteroidal, anti-inflammatory agent derived from the metabolites of bacterial symbionts from entomopathogenic nematodes. ${ }^{35} \mathrm{WBI}-1001$ exerts its anti-inflammatory effects by inhibiting proinflammatory cytokines, including TNF- $\alpha$ and interferon-gamma, and by inhibiting T-cell viability and infiltration processes. ${ }^{35}$

In a Phase II clinical trial of 1\% WBI-1001 cream applied twice daily for the treatment of mild-to-moderate psoriasis, $50 \%$ of patients achieved a PASI-75 at week 12 compared with $4 \%$ in the placebo group $(P<0.0001) .{ }^{35}$ Improvement in PGA and body surface area were also significant, with improvements of $63 \%$ and $79 \%$, respectively, compared with $13 \%$ and $9 \%$ in the placebo group. Reported side effects were mild or moderate.

\section{Recent biologic immunomodulators for psoriasis}

TNF- $\alpha$ inhibitors have been used for years in the treatment of psoriasis with success. With the recent discovery of the 
role of the $\mathrm{T}$ helper (Th)17 pathway in psoriasis, several immunomodulators including anti-IL-12/23, anti-IL-17, and anti-IL-17 receptor agents have emerged and are in development for the treatment of psoriasis.

\section{ThI7 pathway in psoriasis}

When IL-23 binds to its receptor on naïve T-cells, it promotes the development, differentiation and stimulation of a subset of memory CD4+ T-cells known as Th17 cells. ${ }^{7,36-41}$ This signal transduction in Th17 cells occurs through JAK. Activated Th17 cells produce IL-17A, IL-17F, IL-22, and TNF- $\alpha .^{7,37-41}$ IL-17A and IL-17F bind to their receptors on keratinocytes and promote production of numerous proinflammatory cytokines, chemokines, and antimicrobial peptides, including TNF- $\alpha$, that drive the inflammatory response in psoriatic lesions. $^{36-41}$

While IL-17-producing CD4+ T-cells are major participants in the pathogenesis of psoriasis, IL-17 producing CD8+ T-cells (Tc17 cells) may also have an important role. Tc17 cells are present in significantly greater numbers in psoriasis plaques than in skin from healthy individuals. Like Th17 cells, epidermal CD8+ IL-17+ T-cells from psoriasisinflamed skin produce Th17-related cytokines (IL-17, IL-21, and IL-22). ${ }^{7,36-41}$ In addition, these CD8+ IL-17+ T-cells appear to have some resistance to suppression by regulatory T-cells, proliferating much faster than CD8+ IL-17- T-cells. Overall, this selective increase of Tc17 cells in psoriatic skin, particularly in the epidermis, reinforces the claims of previous studies regarding the importances of CD8+ T-cells in the pathogenesis of psoriasis. ${ }^{36-41}$

\section{Anti-IL-I 2/23 agents}

Ustekinumab is a fully human monoclonal antibody directed against the common p40 subunit of IL-12 and IL-23, inflammatory cytokines thought to be important in the pathogenesis of psoriasis. While IL-23 promotes the Th17 pathway, IL-12 perpetuates the Th1 pathway. ${ }^{12,42-46}$ Therefore, ustekinumab prevents the differentiation of naïve T-cells into Th17 and Th1 cells. Ustekinumab is approved by the US Food and Drug Administration for both moderate-to-severe plaque psoriasis and psoriatic arthritis.

The approval of ustekinumab for the treatment of psoriasis was based on Phase I-III clinical trials; however, more recent data continue to support its efficacy. Ustekinumab $45 \mathrm{mg}$ and $90 \mathrm{mg}$ significantly improved health-related quality of life at week 12 compared with placebo in Japanese patients, and improvement was maintained through week $64 .{ }^{47}$ Fifty-nine percent of the patients treated with ustekinumab $45 \mathrm{mg}$ and $68 \%$ of those treated with $90 \mathrm{mg}$ achieved a PASI-75, compared with $7 \%$ of the placebo group, with improvement maintained through week 64 in $65 \%$ and $79 \%$ of actively treated patients, respectively. ${ }^{48}$ Improvement in Nail Psoriasis Severity Index and joint pain at week 64 was also achieved. Results in terms of efficacy and safety in this population was consistent with the findings of two larger trials in which the majority of patients were white. Ustekinumab 45 mg was significantly more effective than placebo, with a PASI-75 achieved in $83 \%$ compared with $11 \%$, respectively, at week 12 in a study of Chinese patients with psoriasis. ${ }^{49}$ Placebo patients crossed over at week 12 and had a response comparable with that of the treatment group at week 28 . Korean and Taiwanese patients with psoriasis were studied using the same study methods, with a decrease in DLQI of 11.2 points in the treatment group compared with 0.5 in the placebo group. ${ }^{50}$ Again, the placebo crossover group achieved similar improvement at week 28. The improvement in DLQI was correlated with improvement in efficacy measures (PASI and PGA). Reported 5-year follow-up safety data on patients who received ustekinumab in these clinical trials showed no apparent increased risk of infections, malignancy, or cardiovascular events. ${ }^{51}$ Recent results from the Psoriasis Longitudinal Assessment and Registry also show a good safety profile, although registry data can be subject to selection bias. ${ }^{52}$

Like ustekinumab, briakinumab is a fully human monoclonal antibody directed against the common p40 subunit of IL-12 and IL-23. Its manufacturer has voluntarily withdrawn it due to concerns regarding major adverse cardiovascular events. ${ }^{53,54}$ Prior to being withdrawn, briakinumab was effective for the treatment of psoriasis in a 52-week study that included an induction phase and a maintenance phase. At the end of a 12 -week induction phase, $76 \%$ of briakinumabtreated patients reached a PGA of clear/minimal and $81 \%$ achieved a PASI-75 compared with $4 \%$ and 5\%, respectively, in the placebo group. ${ }^{53}$ Improved efficacy was achieved with more frequent dosing, with $79 \%$ of the patients who received briakinumab every 4 weeks reaching a PGA of clear/minimal compared with $42 \%$ of those that received the drug every 12 weeks and $6 \%$ of placebo patients. There were more adverse events including serious infections, nonmelanoma skin cancers, and major cardiovascular events in treated patients compared with those who received placebo.

\section{Anti-p 19 subunit of IL-23}

There are two new drugs under development that block p19 subunit of IL-23, with the goal to target the Th17 pathway 
only, blocking IL-23 without the IL-12 blockade associated with ustekinumab. CNTO 1959 and MK-3222 are in Phase II or III trials. Thus far, encouraging results have been recently reported from a Phase 1 study in individuals with moderate-to-severe psoriasis. ${ }^{46-55}$

\section{Apilimod}

Apilimod (formerly STA-5326) is a small molecule in the preliminary stages of study. In a murine model, apilimod inhibited synthesis of IL-12 and IL-23 in myeloid leukocytes and led to suppression of the TH1 but not the TH2 immune response. ${ }^{56}$ In an open-label study, $47 \%$ of patients with psoriasis treated orally with apilimod $70 \mathrm{mg}$ daily achieved a PASI-50 and 53\% achieved a two-point improvement in PGA at 12 weeks. ${ }^{57}$ Study of lesional skin established that apilimod not only suppresses synthesis of IL-12, IL-23, and multiple downstream cytokines, but also concomitantly increases synthesis of the anti-inflammatory cytokine, IL-10.

\section{Anti-IL-I 7 therapy}

The IL-17 pathway includes a family of six cytokines (IL-17A to IL-17F) and five receptors (IL-17RA to IL-17RE). IL-17A and IL-17F are secreted by Th17 cells and other immune cells, including innate lymphoid cells, as disulfide-linked homodimers, but can also form IL-17A/IL-17F heterodimers. IL-17A is about 10-30 times more potent than IL-17F, whereas the IL-17A/IL-17F heterodimer has intermediate activity. ${ }^{36-38,58}$ In psoriatic lesions, IL-17A, the principal effector cytokine of Th17 cells, induces expression of proinflammatory cytokines from several cell types, including epithelial cells. IL-17A is reported to upregulate expression of proinflammatory cytokines (IL-1 $\beta$,
IL-6, TNF- $\alpha$ ) and several chemokines, including CCL20, in human keratinocytes. Induction of CCL 20 by keratinocytes has been suggested as a mechanism that promotes the Th17 pathway. ${ }^{36-38,58}$

IL-17 levels are higher in psoriatic skin than in normal skin. Spontaneous healing or treatment of psoriasis using traditional drugs that do not target IL-17 still ultimately results in reduction of IL-17 in involved skin (Table 2). Although modalities targeting IL-17 are still in development, preliminary data have provided evidence that they are highly effective in the treatment of psoriasis (Figure 1).

\section{Adverse events associated with anti-IL-I 7 therapy}

Although data regarding the adverse effects of anti-IL-17 therapy are limited at this time, this treatment strategy can potentially reduce immunity to intracellular and extracellular micro-organisms and predispose the patients to infectious diseases. ${ }^{59}$ Mucocutaneous candidiasis has been reported as a complication of defects in the IL-17 pathway. ${ }^{60-62}$ One specific adverse event associated with anti-IL-17 therapy is neutropenia. ${ }^{63}$ The exact mechanism for this is not known; however, in animal models, IL-17 is involved in neutrophil homeostasis through granulocyte colony-stimulating factor, and IL-17R-deficient mice have lower levels of neutrophils than do wild-type mice. ${ }^{64,65}$

\section{Anti-IL-I 7 agents}

The focus on the IL-17 pathway has led to development of several anti-IL-17 biologic agents. Phase III clinical trials are underway for secukinumab, a fully human IgG1 monoclonal anti-IL-17A antibody. In Phase II clinical trials, $55 \%$ of patients who received early induction (weeks 0 ,

Table 2 Clinical efficacy and experimental evaluation of therapies indirectly affecting interleukin- 17 in patients with psoriasis

\begin{tabular}{|c|c|c|c|}
\hline Author & Treatment & Experimental evaluation & Conclusion \\
\hline Coimbra et $\mathrm{al}^{66}$ & $\begin{array}{l}\text { NB-UVB and PUVA } \\
\text { phototherapy }\end{array}$ & $\begin{array}{l}\text { Decrease in IL-23, TNF- } \alpha \text {, IL-22, IL-I7, VEGF, } \\
\text { and IL-8 over treatment duration }\end{array}$ & $\begin{array}{l}\text { Phototherapy is clinically effective at reducing } \\
\text { ThI7-related cytokine levels }\end{array}$ \\
\hline $\begin{array}{l}\text { Johnson-Huang } \\
\text { et } \mathrm{al}^{67}\end{array}$ & NB-UVB phototherapy & $\begin{array}{l}\text { Decrease in IL-20, IL-I2/23p40, and IL-23p I9; } \\
\text { reduced IL-I } 7 \text { and IL-22 mRNA expression }\end{array}$ & $\begin{array}{l}\text { NB-UVB radiation therapy can target the IL-I7 } \\
\text { pathway to resolve psoriatic inflammation }\end{array}$ \\
\hline Haider et $\mathrm{al}^{68}$ & Cyclosporine & $\begin{array}{l}\text { Decrease in IL-I7, IFN- } \gamma \text {, and IL- } 22 \text { mRNA } \\
\text { levels }\end{array}$ & $\begin{array}{l}\text { Cyclosporine can reduce Th I7-related } \\
\text { cytokine levels }\end{array}$ \\
\hline Kagami et al ${ }^{69}$ & Infliximab & $\begin{array}{l}\text { Decrease in circulating levels of ThI } 7 \text { and } \\
\text { ThI cells }\end{array}$ & $\begin{array}{l}\text { Infliximab is effective at reducing circulating } \\
\text { ThI } 7 \text { cells }\end{array}$ \\
\hline Caproni et $\mathrm{al}^{70}$ & Etanercept, acitretin & $\begin{array}{l}\text { Etanercept achieved a significant reduction in } \\
\text { IL-I } 7 \text { and IL-22 levels, while acitretin did not }\end{array}$ & $\begin{array}{l}\text { Etanercept is able to reduce ThI7 expression } \\
\text { and is more clinically effective than acitretin }\end{array}$ \\
\hline Zaba et $\mathrm{al}^{71}$ & Etanercept & $\begin{array}{l}\text { Only responders showed suppressed ThI7 } \\
\text { response }\end{array}$ & $\begin{array}{l}\text { Response to etanercept is mediated via } \\
\text { downregulation of IL- I } 7 \text { pathway genes }\end{array}$ \\
\hline
\end{tabular}

Abbreviations: IFN- $\gamma$, interferon-gamma; IL, interleukin; mRNA, messenger ribonucleic acid; NB-UVB, narrowband ultraviolet B; PUVA, psoralen plus ultraviolet A; TNF- $\alpha$, tumor necrosis factor-alpha; VEGF, vascular endothelial growth factor. 


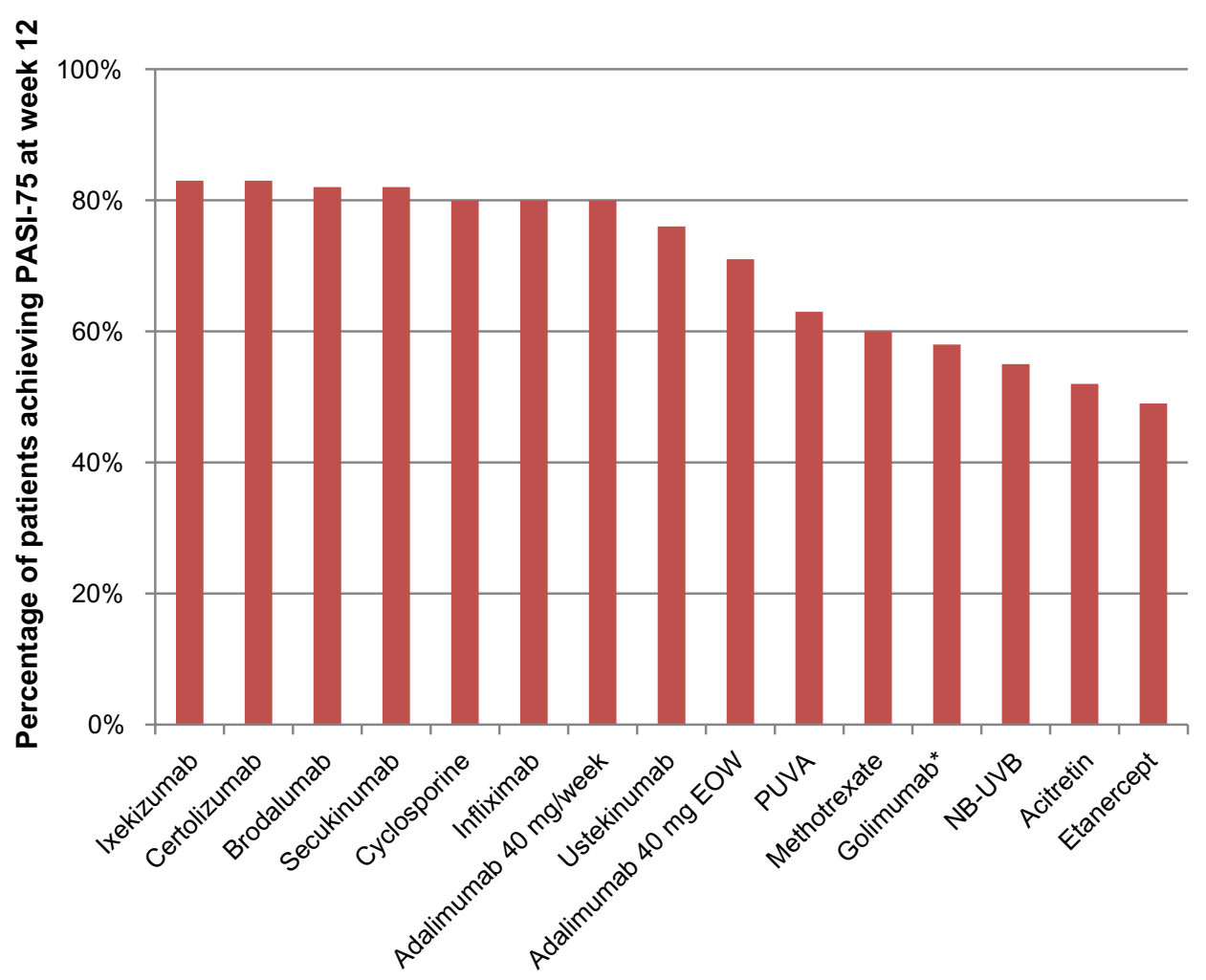

Figure I Efficacy of drugs used for treatment of moderate-to-severe psoriasis.

Notes: The results shown in the figure are related to the drugs used at the following doses: acitretin, $40 \mathrm{mg}$ daily for the first 4 weeks and an individually adjusted dose thereafter; brodalumab, $210 \mathrm{mg}$ at weeks $0,1,2,4,6,8,10$; certolizumab, $400 \mathrm{mg}$ every other week; cyclosporine, 2.5-5 mg/kg/day; etanercept, 50 mg twice weekly; golimumab, $100 \mathrm{mg}$ every 4 weeks; infliximab, $5 \mathrm{mg} / \mathrm{kg}$ at weeks 0,2 , and 6; ixekizumab, $75 \mathrm{mg}$ at weeks 0, 2, 4, and 8; methotrexate, 5-25 mg/week; secukinumab, 75 mg at weeks 0,4 , and 8 ; ustekinumab, $90 \mathrm{mg}$ at weeks 0 and 4 . These results are from individual clinical trials; head-to-head trials have not been performed. *Data for golimumab is related to week 14. Data from Sandoval et al, ${ }^{7}$ Taheri and Feldman, ${ }^{72}$ Papp et al, ${ }^{73}$ and Papp et al. ${ }^{74}$

Abbreviations: EOW, every other week; NB-UVB, narrowband ultraviolet B; PUVA, psoralen + ultraviolet A; PASI-75, 75 percent or more reduction from baseline in the Psoriasis Area and Severity Index.

$1,2,4)$, and $42 \%$ of those who received monthly induction regimens reached a PASI-75, compared with $2 \%$ of placebo patients. ${ }^{75}$ During the maintenance phase, $85 \%$ of patients in the fixed-interval regimen reached a PASI-75 compared with the group of patients that restarted treatment at relapse (67\%). There were no injection site reactions or development of antibodies against the drug, and neutropenia was reported in $5 \%$ of patients receiving the drug during the induction phase and $8 \%$ during the maintenance phase. ${ }^{63}$ In patients with psoriasis who received $75 \mathrm{mg}$ or $150 \mathrm{mg}$ of secukinumab at weeks 0,4 , and $8,82 \%$ reached a PASI75 at week 12 compared with $9 \%$ of placebo patients. ${ }^{74}$ Two patients in the $150 \mathrm{mg}$ group developed transient neutropenia.

In Phase II trials of ixekizumab, a humanized IgG4 monoclonal anti-IL-17A, three doses ( $25 \mathrm{mg}, 75 \mathrm{mg}, 150 \mathrm{mg}$ ) were effective in treating psoriasis compared with placebo at 12 weeks, with $77 \%, 83 \%$, and $82 \%$ of patients, respectively, reaching a PASI-75 compared with $8 \%$ of placebo patients. ${ }^{76}$ There were no significant differences in adverse effects between the treatment groups and placebo. Two patients (one each in the $150 \mathrm{mg}$ group and $75 \mathrm{mg}$ group) developed asymptomatic grade 2 neutropenia. Larger, longer-term studies are needed to support these early findings.

\section{Interleukin- 7 receptor inhibitors}

IL-17A, Il-17F, and IL-17A/F share a common receptor subunit (IL-17RA) for signaling, so by blocking IL-17RA, the proinflammatory actions of these cytokines are inhibited. Brodalumab, another biologic currently in development, is a human anti-IL-17RA monoclonal antibody that binds with high affinity to IL-17RA. In a Phase II trial, four doses of brodalumab, ie, $70 \mathrm{mg}, 140 \mathrm{mg}$, and $210 \mathrm{mg}$ subcutaneously at day 1 and weeks $1,2,4,6,8,10$, or $280 \mathrm{mg}$ subcutaneously at day 1 and weeks 4 and 8 were effective in the treatment of psoriasis: ${ }^{73}$ in the treatment groups, $33 \%, 77 \%$, $82 \%$, and $67 \%$ of patients, respectively, achieved a PASI75 , compared with $0 \%$ in the placebo group. There was a significant improvement in DLQI scores in all treatment groups compared with placebo. Two cases of asymptomatic 
grade 3 neutropenia were reported in the $210 \mathrm{mg}$ group. In a Phase I trial, patients were treated with a single dose of either $140 \mathrm{mg}$ subcutaneously, $350 \mathrm{mg}$ subcutaneously, or $700 \mathrm{mg}$ intravenously, with $38 \%$ and $88 \%$ of patients in the $350 \mathrm{mg}$ and $700 \mathrm{mg}$ groups reaching a PASI-75 by day 43 compared with no patients in the $140 \mathrm{mg}$ and placebo groups. ${ }^{77}$ There were no serious adverse effects.

\section{Discussion}

Although numerous topical and systemic agents are available for the treatment of moderate-to-severe psoriasis, practitioners as well as patients often have difficulty achieving effective control of psoriasis, although without doubt things have improved from the prebiologic era. Development of new medications may potentially help with safer and more effective control of psoriasis in the future. ${ }^{78}$

Several new biologic and small molecule drugs are under investigation for the treatment of psoriasis. The aim is to find drugs that are safer, more effective, easier to use, and more affordable. However, many drugs ultimately fail to reach the market because of lack of efficacy or significant adverse effects. When drugs do get approved, long-term, large studies and data to evaluate the rate of uncommon but possible adverse events associated with their use are often lacking. Newly approved drugs have been withdrawn after years of use due to concerns over rare but major adverse events. ${ }^{7,79}$ It will take considerable time and much study if we are even to find out if the new drugs in development are safer than the biologics currently available.

Considering that no drug can "cure" psoriasis, the toxicity of antipsoriatic drugs is an important consideration influencing long-term treatment preferences. Many practitioners and patients may be hesitant to use new medications for years after their approval, preferring to wait until the long-term safety profiles of these therapies are available.

Another consideration is that clinical trials of new drugs often do not adequately reflect real-world practice. The effects of these medications in real-world patients, often with comorbidities, may be different than in a controlled setting. Additionally, the risk/benefit ratio of these drugs should be compared with other available treatments, which may be much cheaper, to establish their benefit to the antipsoriatic armamentarium. In general, head-to-head trials of psoriasis drugs are lacking.

Despite many potential obstacles in the path of development and use of new medications, emerging biologics, including anti-IL-17 agents, appear to be highly effective and have a better safety profile than traditional systemic antipsoriatic drugs. ${ }^{7}$ The specificity these treatments have in a small subset of cells may potentially result in fewer adverse effects than other nonspecific treatment modalities, especially traditional immunosuppressants. ${ }^{7}$ Neutropenia is a possible adverse effect of anti-IL-17 therapy; however, most cases are uncomplicated, subclinical, and asymptomatic.

\section{Conclusion}

Research and development of new therapies for the treatment of psoriasis has largely focused on biologic agents. Studies of the anti-IL-17 agents are thus far encouraging, and these drugs have great potential to become another option in the treatment of psoriasis. New oral agents in development also have the potential to play a role in the treatment of psoriasis, providing a safer option compared with current oral therapies. These new treatments will provide both the practitioner and the patient with more choices and opportunities for individualized treatment regimes that will lead to better outcomes.

\section{Disclosure}

The Center for Dermatology Research is supported by an unrestricted educational grant from Galderma Laboratories, LP. SRF is a consultant and speaker for Galderma, Stiefel/GlaxoSmithKline, Abbott Labs, Warner Chilcott, Janssen, Amgen, Photomedex, Genentech, BiogenIdec, and Bristol Myers Squibb. He has received grants from Galderma, Astellas, Abbott Labs, Warner Chilcott, Janssen, Amgen, Photomedex, Genentech, BiogenIdec, Coria/Valeant, Pharmaderm, Ortho Pharmaceuticals, Aventis Pharmaceuticals, Roche Dermatology, 3M, Bristol Myers Squibb, Stiefel/GlaxoSmithKline, Novartis, Medicis, Leo, HanAll Pharmaceuticals, Celgene, Basilea, and Anacor and has received stock options from Photomedex. He is the founder and holds stock in Causa Research. The other authors have no conflicts of interest to disclose.

\section{References}

1. Parisi R, Symmons DP, Griffiths CE, Ashcroft DM. Global epidemiology of psoriasis: a systematic review of incidence and prevalence. J Invest Dermatol. 2013;133(2):377-385.

2. Reich K, Kruger K, Mossner R, Augustin M. Epidemiology and clinical pattern of psoriatic arthritis in Germany: a prospective interdisciplinary epidemiological study of 1511 patients with plaque-type psoriasis. $\mathrm{Br} J$ Dermatol. 2009;160(5):1040-1047.

3. Boehncke WH, Boehncke S. Cardiovascular mortality in psoriasis and psoriatic arthritis: epidemiology, pathomechanisms, therapeutic implications, and perspectives. Curr Rheumatol Rep. 2012;14(4): 343-348.

4. Valenzuela F, Silva P, Valdes MP, Papp K. Epidemiology and quality of life of patients with psoriasis in Chile. Actas Dermosifiliogr. 2011;102(10):810-816. 
5. Papp K, Valenzuela F, Poulin Y, Bernstein G, Wasel N. Epidemiology of moderate-to-severe plaque psoriasis in a Canadian surveyed population. J Cutan Med Surg. 2010;14(4):167-174.

6. Papoutsaki M, Costanzo A. Treatment of psoriasis and psoriatic arthritis. BioDrugs. 2013;27 Suppl 1:3-12.

7. Sandoval LF, Pierce A, Feldman SR. Systemic therapies for psoriasis: an evidence-based update. Am J Clin Dermatol. February 5, 2014. [Epub ahead of print.]

8. Raut AS, Prabhu RH, Patravale VB. Psoriasis clinical implications and treatment: a review. Crit Rev Ther Drug Carrier Syst. 2013;30(3): $183-216$.

9. Hsu S, Papp KA, Lebwohl MG, et al. Consensus guidelines for the management of plaque psoriasis. Arch Dermatol. 2012;148(1):95-102.

10. Baker C, Mack A, Cooper A, et al. Treatment goals for moderate to severe psoriasis: an Australian consensus. Australas J Dermatol. 2013;54(2):148-154.

11. Krupashankar DS, Dogra S, Kura M, et al. Efficacy and safety of itolizumab, a novel anti-CD6 monoclonal antibody, in patients with moderate to severe chronic plaque psoriasis: results of a double-blind, randomized, placebo-controlled, phase-III study. J Am Acad Dermatol. April 2, 2014. [Epub ahead of print.]

12. Laws PM, Young HS. Current and emerging systemic treatment strategies for psoriasis. Drugs. 2012;72(14):1867-1880.

13. Gooderham M. Small molecules: an overview of emerging therapeutic options in the treatment of psoriasis. Skin Therapy Lett. 2013;18(7):1-4.

14. Patel M, Day A, Warren RB, Menter A. Emerging therapies for the treatment of psoriasis. Dermatol Ther (Heidelb). 2012;2(1):16.

15. Ochaion A, Bar-Yehuda S, Cohen S, et al. The anti-inflammatory target $\mathrm{A}(3)$ adenosine receptor is over-expressed in rheumatoid arthritis, psoriasis and Crohn's disease. Cell Immunol. 2009;258(2):115-122.

16. David M, Akerman L, Ziv M, et al. Treatment of plaque-type psoriasis with oral CF 101: data from an exploratory randomized phase 2 clinical trial. J Eur Acad Dermatol Venereol. 2012;26(3):361-367.

17. Fishman P, Bar-Yehuda S, Liang BT, Jacobson KA. Pharmacological and therapeutic effects of A3 adenosine receptor agonists. Drug Discov Today. 2012;17(7-8):359-366.

18. Garcia-Perez ME, Stevanovic T, Poubelle PE. New therapies under development for psoriasis treatment. Curr Opin Pediatr. 2013;25(4):480-487.

19. Jacobson KA, Klutz AM, Tosh DK, Ivanov AA, Preti D, Baraldi PG. Medicinal chemistry of the A3 adenosine receptor: agonists, antagonists, and receptor engineering. Handb Exp Pharmacol. 2009;(193):123-159.

20. Andres RM, Hald A, Johansen C, Kragballe K, Iversen L. Studies of Jak/STAT3 expression and signalling in psoriasis identifies STAT3Ser727 phosphorylation as a modulator of transcriptional activity. Exp Dermatol. 2013;22(5):323-328.

21. Kwatra SG, Dabade TS, Gustafson CJ, Feldman SR. JAK inhibitors in psoriasis: a promising new treatment modality. J Drugs Dermatol. 2012;11(8):913-918.

22. Menter A, Papp KA, Tan H, Tyring S, Wolk R, Buonanno M. Efficacy of tofacitinib, an oral janus kinase inhibitor, on clinical signs of moderate-to-severe plaque psoriasis in different body regions. $J$ Drugs Dermatol. 2014;13(3):252-256.

23. Ortiz-Ibanez K, Alsina MM, Munoz-Santos C. Tofacitinib and other kinase inhibitors in the treatment of psoriasis. Actas Dermosifiliogr. 2013;104(4):304-310.

24. Papp KA, Menter A, Strober B, et al. Efficacy and safety of tofacitinib, an oral Janus kinase inhibitor, in the treatment of psoriasis: a Phase $2 b$ randomized placebo-controlled dose-ranging study. $\mathrm{Br} J$ Dermatol. 2012;167(3):668-677.

25. Strober B, Buonanno M, Clark JD, et al. Effect of tofacitinib, a Janus kinase inhibitor, on haematological parameters during 12 weeks of psoriasis treatment. Br J Dermatol. 2013;169(5):992-999.

26. Ports WC, Khan S, Lan S, et al. A randomized phase 2a efficacy and safety trial of the topical Janus kinase inhibitor tofacitinib in the treatment of chronic plaque psoriasis. Br J Dermatol. 2013;169(1):137-145.
27. Punwani N, Scherle P, Flores R, et al. Preliminary clinical activity of a topical JAK1/2 inhibitor in the treatment of psoriasis. J Am Acad Dermatol. 2012;67(4):658-664.

28. Gottlieb AB, Matheson RT, Menter A, et al. Efficacy, tolerability, and pharmacodynamics of apremilast in recalcitrant plaque psoriasis: a phase II open-label study. J Drugs Dermatol. 2013; 12(8):888-897.

29. Papp K, Cather JC, Rosoph L, et al. Efficacy of apremilast in the treatment of moderate to severe psoriasis: a randomised controlled trial. Lancet. 2012;380(9843):738-746.

30. Wittmann M, Helliwell PS. Phosphodiesterase 4 inhibition in the treatment of psoriasis, psoriatic arthritis and other chronic inflammatory diseases. Dermatol Ther (Heidelb). 2013;3(1):1-15.

31. Palfreeman AC, McNamee KE, McCann FE. New developments in the management of psoriasis and psoriatic arthritis: a focus on apremilast. Drug Des Devel Ther. 2013;7:201-210.

32. Shutty B, West C, Pellerin M, Feldman S. Apremilast as a treatment for psoriasis. Expert Opin Pharmacother. 2012;13(12):1761-1770.

33. Strand V, Fiorentino D, Hu C, Day RM, Stevens RM, Papp KA. Improvements in patient-reported outcomes with apremilast, an oral phosphodiesterase 4 inhibitor, in the treatment of moderate to severe psoriasis: results from a phase IIb randomized, controlled study. Health Qual Life Outcomes. 2013;11:82.

34. Grogan K. Celgene's apremilast succeeds in Phase III psoriasis trial. PharmaTimes. 2013. Available from: http://www.pharmatimes.com/ article/13-03-03/Celgene_s_apremilast_succeeds_in_Phase_III_ psoriasis_trial.aspx. Accessed May 10, 2014.

35. Bissonnette R, Bolduc C, Maari C, et al. Efficacy and safety of topical WBI-1001 in patients with mild to moderate psoriasis: results from a randomized double-blind placebo-controlled, phase II trial. J Eur Acad Dermatol Venereol. 2012;26(12):1516-1521.

36. Lynde CW, Poulin Y, Vender R, Bourcier M, Khalil S. Interleukin 17A: toward a new understanding of psoriasis pathogenesis. $J$ Am Acad Dermatol. 2014;71(1):141-150.

37. Gaffen SL. Structure and signalling in the IL-17 receptor family. Nat Rev Immunol. 2009;9(8):556-567.

38. Cai Y, Shen X, Ding C, et al. Pivotal role of dermal IL-17-producing gammadelta $\mathrm{T}$ cells in skin inflammation. Immunity. 2011;35(4): 596-610.

39. Boniface K, Blom B, Liu YJ, de Waal MR. From interleukin-23 to T-helper 17 cells: human T-helper cell differentiation revisited. Immunol Rev. 2008;226:132-146.

40. Guilloteau K, Paris I, Pedretti N, et al. Skin inflammation induced by the synergistic action of IL-17A, IL-22, oncostatin M, IL-1 \{alpha\}, and TNF-\{alpha\} recapitulates some features of psoriasis. J Immunol. 2010;184(9):5263-5270.

41. Wilson NJ, Boniface K, Chan JR, et al. Development, cytokine profile and function of human interleukin 17-producing helper T cells. Nat Immunol. 2007;8(9):950-957.

42. Novelli L, Chimenti MS, Chiricozzi A, Perricone R. The new era for the treatment of psoriasis and psoriatic arthritis: perspectives and validated strategies. Autoimmun Rev. 2014;13(1):64-69.

43. Villasenor-Park J, Wheeler D, Grandinetti L. Psoriasis: evolving treatment for a complex disease. Cleve Clin J Med. 2012;79(6):413-423.

44. Kupetsky EA, Mathers AR, Ferris LK. Anti-cytokine therapy in the treatment of psoriasis. Cytokine. 2013;61(3):704-712.

45. Ariza ME, Williams MV, Wong HK. Targeting IL-17 in psoriasis: from cutaneous immunobiology to clinical application. Clin Immunol. 2013;146(2):131-139.

46. Johnson-Huang LM, Lowes MA, Krueger JG. Putting together the psoriasis puzzle: an update on developing targeted therapies. Dis Model Mech. 2012;5(4):423-433.

47. Nakagawa H, Schenkel B, Kato M, Kato T, Igarashi A. Impact of ustekinumab on health-related quality of life in Japanese patients with moderate-to-severe plaque psoriasis: results from a randomized, double-blind, placebo-controlled phase $2 / 3$ trial. J Dermatol. 2012;39(9):761-769. 
48. Igarashi A, Kato T, Kato M, Song M, Nakagawa H. Efficacy and safety of ustekinumab in Japanese patients with moderate-to-severe plaque-type psoriasis: long-term results from a phase $2 / 3$ clinical trial. J Dermatol. 2012;39(3):242-252.

49. Zhu X, Zheng M, Song M, et al. Efficacy and safety of ustekinumab in Chinese patients with moderate to severe plaque-type psoriasis: results from a phase 3 clinical trial (LOTUS). J Drugs Dermatol. 2013;12(2): $166-174$.

50. Tsai TF, Song M, Shen YK, et al. Ustekinumab improves health-related quality of life in Korean and Taiwanese patients with moderate to severe psoriasis: results from the PEARL trial. J Drugs Dermatol. 2012;11(8):943-949

51. Papp KA, Griffiths CE, Gordon K, et al. Long-term safety of ustekinumab in patients with moderate-to-severe psoriasis: final results from 5 years of follow-up. Br J Dermatol. 2013;168(4):844-854.

52. Papp KA, Strober B, Augustin M, Calabro S, Londhe A, Chevrier M. PSOLAR: design, utility, and preliminary results of a prospective, international, disease-based registry of patients with psoriasis who are receiving, or are candidates for, conventional systemic treatments or biologic agents. J Drugs Dermatol. 2012;11(10):1210-1217.

53. Gordon KB, Langley RG, Gottlieb AB, et al. A phase III, randommoderate-to-severe psoriasis. J Invest Dermatol. 2012;132(2):304-314.

54. Papp KA, Sundaram M, Bao Y, et al. Effects of briakinumab treatment for moderate to severe psoriasis on health-related quality of life and work productivity and activity impairment: results from a randomized phase III study. J Eur Acad Dermatol Venereol. 2014;28(6):790-798.

55. Levin AA, Gottlieb AB. Specific targeting of interleukin-23p19 as effective treatment for psoriasis. J Am Acad Dermatol. 2014;70(3): 555-561.

56. Wada Y, Lu R, Zhou D, et al. Selective abrogation of Th1 response by STA-5326, a potent IL-12/IL-23 inhibitor. Blood. 2007;109(3): $1156-1164$.

57. Wada Y, Cardinale I, Khatcherian A, et al. Apilimod inhibits the production of IL-12 and IL-23 and reduces dendritic cell infiltration in psoriasis. PLoS One. 2012;7(4):e35069.

58. Kirkham BW, Kavanaugh A, Reich K. Interleukin-17A: a unique pathway in immune-mediated diseases: psoriasis, psoriatic arthritis and rheumatoid arthritis. Immunology. 2014;141(2):133-142.

59. Sillevis Smitt JH, Kuijpers TW. Cutaneous manifestations of primary immunodeficiency. Curr Opin Pediatr. 2013;25(4):492-497.

60. Huppler AR, Bishu S, Gaffen SL. Mucocutaneous candidiasis: the IL-17 pathway and implications for targeted immunotherapy. Arthritis Res Ther. 2012;14(4):217.

61. Khosravi AR, Shokri H, Darvishi S. Altered immune responses in patients with chronic mucocutaneous candidiasis. J Mycol Med. 2014;24(2):135-140.

62. Huston DP. Defects in interleukin-17 immunity in the pathogenesis of chronic mucocutaneous candidiasis. Curr Allergy Asthma Rep. 2011;11(5):342-344.

63. Ye P, Rodriguez FH, Kanaly S, et al. Requirement of interleukin 17 receptor signaling for lung $\mathrm{CXC}$ chemokine and granulocyte colony-stimulating factor expression, neutrophil recruitment, and host defense. J Exp Med. 2001;194(4):519-527.

64. Smith E, Stark MA, Zarbock A, et al. IL-17A inhibits the expansion of IL-17A-producing T cells in mice through "short-loop" inhibition via IL-17 receptor. J Immunol. 2008;181(2):1357-1364. ized, controlled trial of the fully human IL-12/23 mAb briakinumab in

65. von Vietinghoff S, Ley K. Homeostatic regulation of blood neutrophil counts. J Immunol. 2008;181(8):5183-5188.

66. Coimbra S, Oliveira H, Reis F, et al. Interleukin (IL)-22, IL-17, IL-23, IL-8, vascular endothelial growth factor and tumour necrosis factoralpha levels in patients with psoriasis before, during and after psoralenultraviolet A and narrowband ultraviolet B therapy. $\mathrm{Br} J$ Dermatol. 2010;163(6):1282-1290.

67. Johnson-Huang LM, Suarez-Farinas M, Sullivan-Whalen M, Gilleaudeau P, Krueger JG, Lowes MA. Effective narrow-band UVB radiation therapy suppresses the IL-23/IL-17 axis in normalized psoriasis plaques. J Invest Dermatol. 2010;130(11):2654-2663.

68. Haider AS, Lowes MA, Suarez-Farinas M, et al. Identification of cellular pathways of "type 1," Th17 T cells, and TNF- and inducible nitric oxide synthase-producing dendritic cells in autoimmune inflammation through pharmacogenomic study of cyclosporine A in psoriasis. J Immunol. 2008;180(3):1913-1920.

69. Kagami S, Rizzo HL, Lee JJ, Koguchi Y, Blauvelt A. Circulating Th17, Th22, and Th1 cells are increased in psoriasis. J Invest Dermatol. 2010;130(5):1373-1383.

70. Caproni M, Antiga E, Melani L, Volpi W, Del Bianco E, Fabbri P. Serum levels of IL-17 and IL-22 are reduced by etanercept, but not by acitretin, in patients with psoriasis: a randomized-controlled trial. J Clin Immunol. 2009;29(2):210-214.

71. Zaba LC, Suarez-Farinas M, Fuentes-Duculan J, et al. Effective treatment of psoriasis with etanercept is linked to suppression of IL-17 signaling, not immediate response TNF genes. J Allergy Clin Immunol. 2009;124(5):1002-1010. e1-e395.

72. Taheri A, Feldman SR. Biologics in practice: how effective are biologics. Dermatologist. 2012;20(11):34-38.

73. Papp KA, Leonardi C, Menter A, et al. Brodalumab, an anti-interleukin-17-receptor antibody for psoriasis. $N \mathrm{Engl} \mathrm{J} \mathrm{Med}$. 2012;366(13):1181-1189.

74. Papp KA, Langley RG, Sigurgeirsson B, et al. Efficacy and safety of secukinumab in the treatment of moderate-to-severe plaque psoriasis: a randomized, double-blind, placebo-controlled phase II dose-ranging study. Br J Dermatol. 2013;168(2):412-421.

75. Rich P, Sigurgeirsson B, Thaci D, et al. Secukinumab induction and maintenance therapy in moderate-to-severe plaque psoriasis: a randomized, double-blind, placebo-controlled, phase II regimenfinding study. Br J Dermatol. 2013;168(2):402-411.

76. Leonardi C, Matheson R, Zachariae C, et al. Anti-interleukin-17 monoclonal antibody ixekizumab in chronic plaque psoriasis. $N$ Engl J Med. 2012;366(13):1190-1199.

77. Papp KA, Reid C, Foley P, et al. Anti-IL-17 receptor antibody AMG 827 leads to rapid clinical response in subjects with moderate to severe psoriasis: results from a phase I, randomized, placebo-controlled trial. J Invest Dermatol. 2012;132(10):2466-2469.

78. Gudjonsson JE, Johnston A, Ellis CN. Novel systemic drugs under investigation for the treatment of psoriasis. $J$ Am Acad Dermatol. 2012;67(1):139-147.

79. Agrawal U, Gupta M, Dube D, Vyas SP. Options and opportunities for clinical management and treatment of psoriasis. Crit Rev Ther Drug Carrier Syst. 2013;30(1):51-90.

\section{Dovepress}

\section{Publish your work in this journal}

Psoriasis: Targets and Therapy is international, peer-reviewed, open access journal focusing on psoriasis, nail psoriasis, psoriatic arthritis and related conditions, identification of therapeutic targets and the optimal use of integrated treatment interventions to achieve improved outcomes and quality of life. The manuscript management system

is completely online and includes a very quick and fair peer-review system. Visit http://www.dovepress.com/testimonials.php to read real quotes from published authors. 